\title{
Clinical analysis of orthostatic headache in Korean patients
}

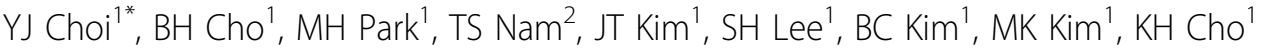 \\ From The European Headache and Migraine Trust International Congress \\ London, UK. 20-23 September 2012
}

\section{Introduction}

Orthostatic headache is defined as a headache that is significantly worsened in the standing position and relieved with recumbency. The major cause of orthostatic headaches is cerebrospinal fluid (CSF) leak. But orthostatic headache also occurs in variable diseases. Therefore clinical manifestations, MRI findings, and outcomes are seems to be various.

\section{Objectives}

We analyzed clinical and radiological differences between favorable and non-favorable groups.

\section{Methods}

We reviewed 45 patients with orthostatic headache. All patients were underwent brain MRI. CSF tapping and radioisotope cisternography was performed as occasion demands. All patients were performed conservative therapy. Autologous blood patch was done in patients who did not respond to conservative therapy. We divided patients to two groups, favorable (F), unfavorable (UF) groups. The F group defined as clinical improvement by conservative therapy, or once trial of blood patch. More than 14 days of hospitalization, two more trials of blood patch, or relapse defined as UF group.

\section{Results}

21 of 45 patients were classified as a F group. There were no significant differences in age between two groups. The F group had short hospitalization period ( 7.5 days vs 16.0 days, $\mathrm{p}=0.009$ ). The UF group had more abnormal MR findings ( 5 vs $17, \mathrm{p}<0.001$ ). There were 1 platybasia, 1 skull base tumor, 1 Chiari I malformation, 1 enhancement of dural and epidural layer of thoracic spine, 3 pituitary enlargement, 3 sagging brain and 4 subdural hemorrhages in UF group. 12 of UF group showed pachymeningeal enhancement in brain MRI (3 patients in F group, $\mathrm{p}<0.001)$. 16 of $\mathrm{F}$ group and 7 of UF group showed normal MRI. 1 of 16 normal MRI in F group and 5 of 7 normal MRI in UF group had CSF leakage on non-lumbar lesion $(\mathrm{p}<0.001)$.

\section{Conclusions}

Orthostatic headache presenting unfavorable outcome had more brain MRI abnormalities and CSF leakage on upper spinal level. Due to small in number of cases, further recruit of patients is needed.

\section{Author details}

${ }^{1}$ Chonnam National University Hospital, Korea, Republic of China. ${ }^{2}$ Chonnam National University Hwasun Hospital, Korea, Republic of China.

Published: 21 February 2013

\section{References}

1. Schievink WI: Spontaneous spinal cerebrospinal fluid leaks and intracranial hypotension. JAMA 2006, 295:2284-2296.

2. Schievink WI, Gordon OK, Tourje J: Connective tissue disorders with spontaneous spinal cerebrospinal fluid leaks and intracranial hypotension: a prospective study. Neurosurgery 2004, 54:65-71.

3. Schievink WI, Louy C: Precipitating factors of spontaneous spinal CSF leaks and intracranial hypotension. Neurology 2007, 69:700-02.

doi:10.1186/1129-2377-14-S1-P153

Cite this article as: Choi et al: Clinical analysis of orthostatic headache in Korean patients. The Journal of Headache and Pain 2013

14(Suppl 1):P153. 